\title{
Erratum to: Magma mixing in the 1100 AD Montaña Reventada composite lava flow, Tenerife, Canary Islands: interaction between rift zone and central volcano plumbing systems
}

\author{
S. Wiesmaier - F. M. Deegan • V. R. Troll • \\ J. C. Carracedo · J. P. Chadwick - D. M. Chew
}

Published online: 19 July 2011

(C) Springer-Verlag 2011

Erratum to: Contrib Mineral Petrol

DOI 10.1007/s00410-010-0596-x

The original article was published incorrectly with an error in Table 1. The corrected and complete version is now provided below, which include the correct $\mathrm{Pb}$ concentrations along with $\mathrm{Nb}$ concentrations. We gratefully acknowledge the help of Dr. Mike Norry in pointing out this mistake.

The online version of the original article can be found under doi:10.1007/s00410-010-0596-x.

\footnotetext{
S. Wiesmaier $(\varangle) \cdot$ D. M. Chew

Department of Geology, Trinity College Dublin,

2 College Green, Dublin 2, Ireland

e-mail: wiesmais@tcd.ie

F. M. Deegan · V. R. Troll

Department of Earth Sciences, Uppsala University,

Villavägen 16, 75236 Uppsala, Sweden

J. C. Carracedo

Estación Volcanológica de Canarias, IPNA-CSIC,

Av. Astrofísica Francisco Sanchez 3,

38206 La Laguna, Tenerife, Spain

J. P. Chadwick

Department of Petrology (FALW), Vrjie Universiteit,

1081 HV Amsterdam, The Netherlands
} 


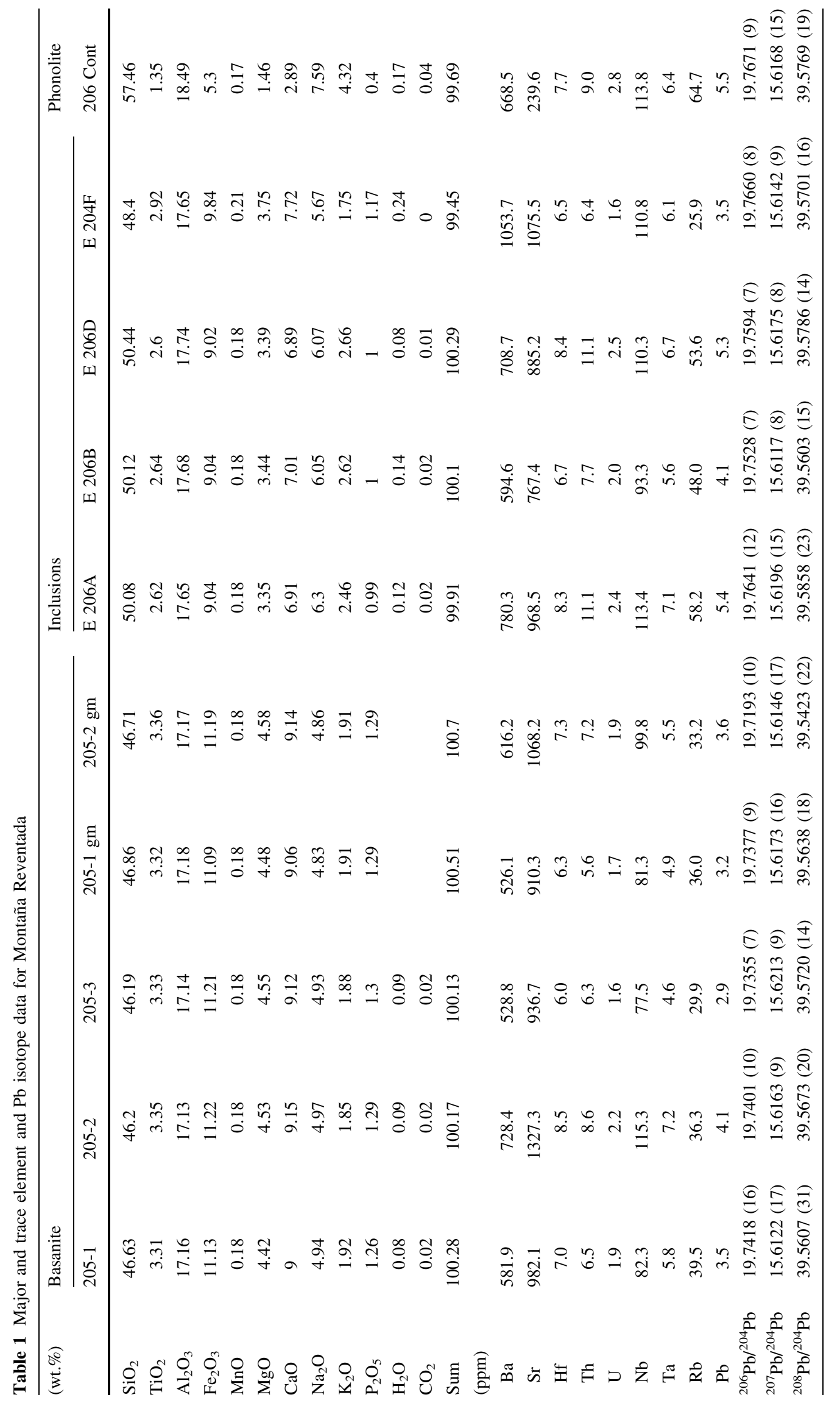




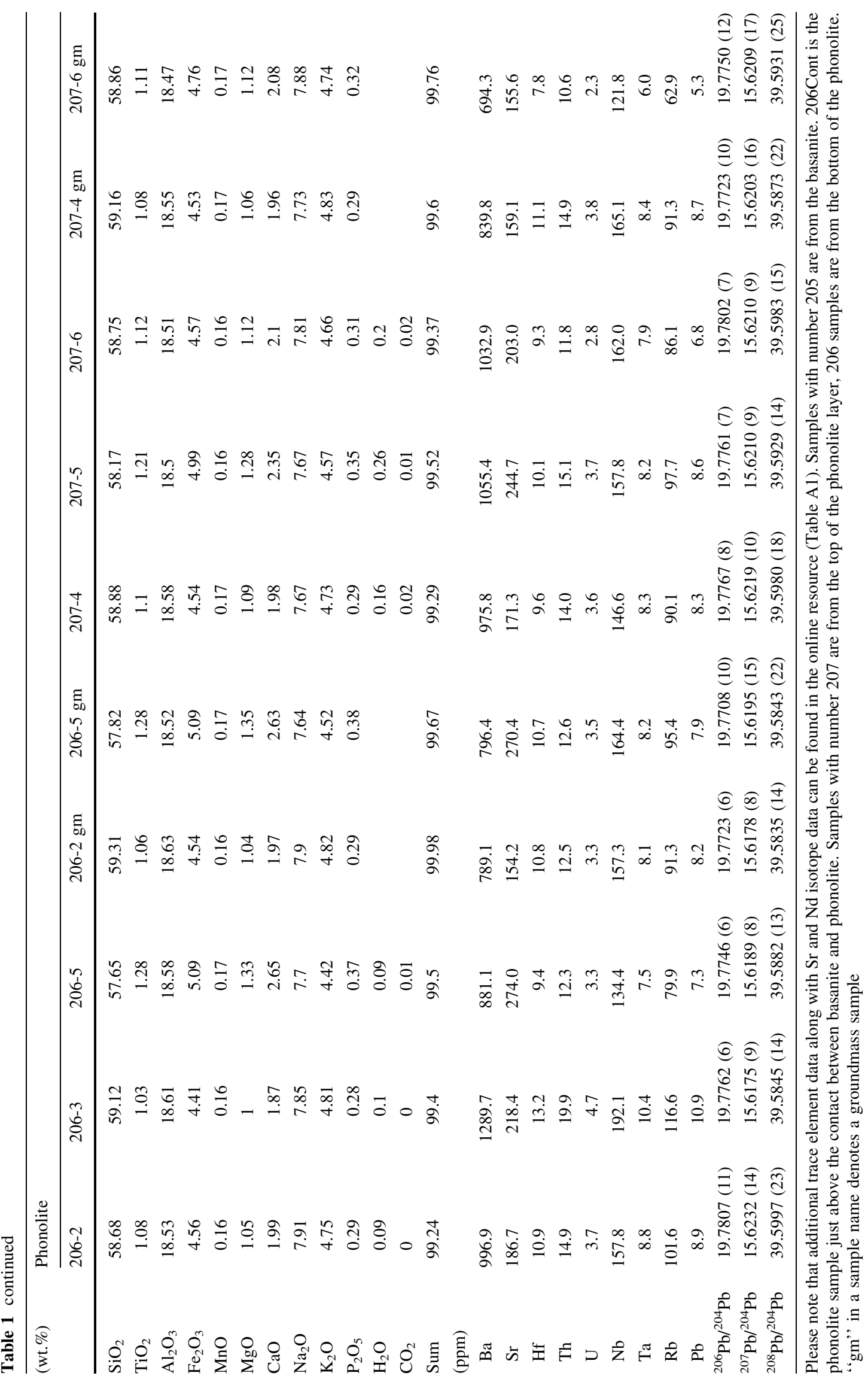

